\title{
Superior subconjunctival dislocation of intraocular lens following blunt trauma: A rare case report Gupta S, ${ }^{1}$ Yadav R, ${ }^{\text {iD }}$ Shrestha S, ${ }^{1}$ Bista B, ${ }^{2}$ Gupta V, ${ }^{2}$ Chaudhary S $^{3}$
}

${ }^{1}$ Sharad Gupta, Consultant Ophthalmologist; ${ }^{1}$ Reena Yadav, Consultant Ophthalmologist; ${ }^{1}$ Satbodh Shrestha, Consultant Ophthalmologist; ${ }^{2}$ Bipin Bista, Anterior segment fellow; ${ }^{2}$ Vidisha Gupta, Anterior segment fellow; ${ }^{3}$ Sushma Chaudhary, Optometrist, Sagarmatha Choudhary Eye Hospital, Lahan, Siraha, Nepal.

\begin{abstract}
Subconjunctival dislocation of the intraocular lens secondary to trauma is an unusual and serious condition in the pseudophakic eye. Here, a case of 75 years old male who had traumatic superior subconjunctival dislocation of intraocular lens to his right eye with cow's horn is reported. The patient was managed with surgical extraction of the lens and planned for secondary intraocular lens implantation. It is quite challenging to manage such a case. Despite, proper surgical management visual outcomes are always guarded in such patients with blunt trauma.
\end{abstract}

Key words: Blunt ocular trauma; Intraocular lens; Lens implantation; Superior subconjunctival dislocation.

\section{INTRODUCTION}

$\mathrm{D}$ islocation of intraocular lens (IOL) also coined "pseudo phacocele" following ocular blunt trauma is rare. ${ }^{1}$ Previous literatures have reported traumatic dislocation of IOL into subconjunctival space, vitreous cavity, and even in supra-choroidal space. ${ }^{2-4}$ Traumatic subconjunctival dislocation of anterior chamber IOL has also been reported. ${ }^{5}$ Anterior dislocation of scleral fixated IOL, following blunt trauma by cricket ball, has also been reported. ${ }^{6}$ Here, a case of superior subconjunctival dislocation of IOL following blunt ocular trauma in a

\section{Access this article online}

Website: www.jkmc.com.np

DOI: https://doi.org/10.3126/jkmc.v10i2.40069

\section{HOW TO CITE}

Gupta S, Yadav R, Shrestha S, Bista B, Gupta V. Superior subconjunctival dislocation of intraocular lens following blunt trauma: A rare case report. J Kathmandu Med Coll. 2021;10(2):98100.

Address for correspondence

Dr. Sharad Gupta

Consultant Ophthalmologist

Sagarmatha Choudhary Eye Hospital,

Lahan, Siraha, Nepal.

E-mail: sharadgupta00839@gmail.com

Copyright ๔ 2021 Journal of Kathmandu Medical College (JKMC)

ISSN: 2019-1785 (Print), 2091-1793 (Online)

(i) S This work is licensed under a Creative Commons Attribution-Non Commercial 4.0 International License. 75-year-old male. It is an emergency condition and quite challenging to manage such cases however early intervention improves visual outcomes.?

\section{CASE REPORT}

A 75-year-old male presented to the emergency department with chief complaints of redness, pain, and diminution of vision in his right eye following trauma with cow's horn one week back. He underwent small incision cataract surgery with polymethyl-methacrylate (PMMA) $\mathrm{IOL}$ implantation three years back in his right eye. At the time of presentation, visual acuity was the perception of light and 3/60 in the right and left eye respectively. Ophthalmic examination of the right eye showed soft eyeball and no conjunctival lacerations. The bulbar conjunctiva had a subconjunctival haemorrhage, iris tissue, and bulging of conjunctival haematoma at 12 to two o'clock of limbus (Figure 1). Slit lamp biomicroscopic examination of the right eye revealed traumatic pseudo phacocele with a sign "golden half ring," in superior bulbar conjunctiva suggesting the presence of posterior chamber IOL $(\mathrm{PCIOL})$ in subconjunctival space (Figure 2). There was mild corneal oedema along with Descemet's folds. Anterior and posterior segment complete examination could not be done due to total hyphaema obscuring the view. Intraocular pressure was $7 \mathrm{mmHg}$ in the right eye and $20 \mathrm{mmHg}$ in the left eye. Ultrasonography B Scan was done which showed mild vitreous haemorrhage with intact retina. Anterior and posterior segment examination of the left eye was 
unremarkable except nucleus sclerosis grade three. The patient was planned for surgery. Superior peritomy was done, $\mathrm{PCIOL}$ along with prolapsed iris tissue was removed from subconjunctival space. Traumatic dislocation of $\mathrm{IOL}$ into superior subconjunctival space might be from the incision site (wound dehiscence) what was found in this case. Then 360 peritomy along with thorough wound exploration was done in all quadrants to see the site of

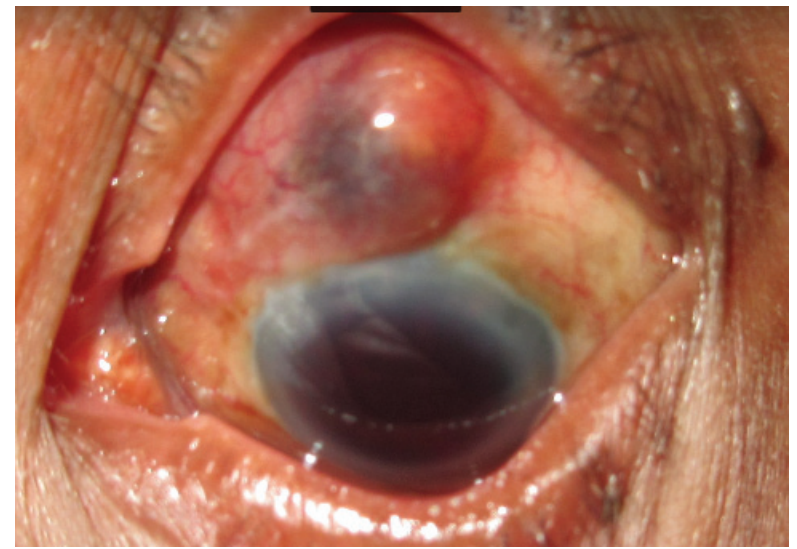

Figure 1: Slit lamp photograph showing hyphaema with bluish discolouration due to iris tissue in the superior bulbar conjunctiva

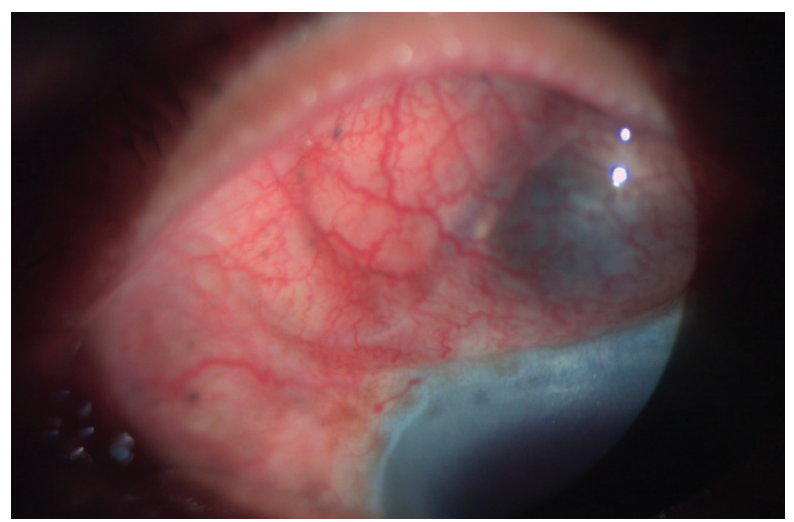

Figure 2: Diffuse illumination slit lamp photograph showing the $\mathrm{PCIOL}$ in subconjunctival space

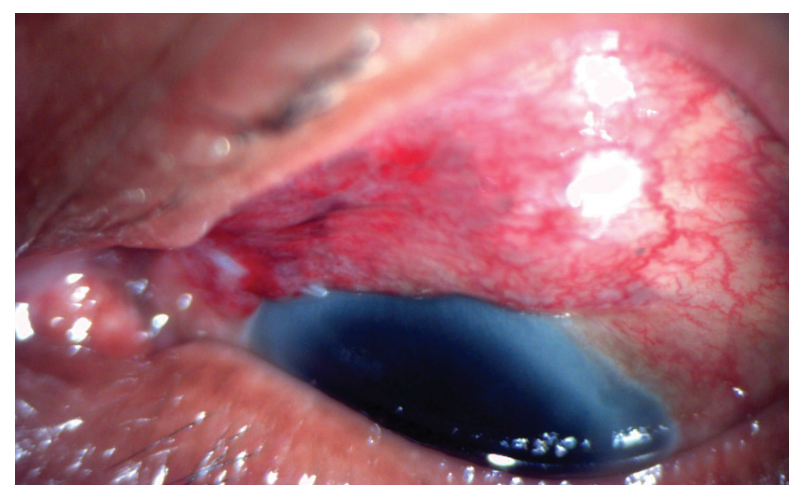

Figure 3: Post IOL removal and wound dehiscence repair globe rupture but no sign of globe rupture was seen. Anterior vitrectomy and hyphaema wash were done. Incision site (wound dehiscence) and conjunctiva was sutured with 8-0 Vicryl. On the first postoperative day, his vision was perception was light (Figure 3). The patient was discharged with topical steroids and antibiotics and was asked to follow-up after one month for secondary IOL implantation if possible.

\section{DISCUSSION}

Displacement of intraocular lens in pseudophakic eye also known as pseudo phacocele was first described by Biedner et al. in 1977 in a patient who underwent intracapsular cataract surgery with iris clip lens implantation. ${ }^{8}$ Subconjunctival dislocation of $\mathrm{IOL}$ following trauma is rare and serious complication. Various factors determine the management of dislocated $\mathrm{IOL}$ and visual outcomes such as time of presentation, ocular infection, the status of cornea, posterior capsule status, vitreous loss and associated intraocular damage. ${ }^{9,10}$ The main aim of management would be to restore globe integrity. Despite prognostic factors, it is mandatory to remove the PCIOL and repair wound dehiscence or scleral rupture in order to minimise risk of endophthalmitis. Visual acuity at presentation and timing of presentation, condition of the iris and uveal tissue, the amount of vitreous loss, retinal detachment (RD), associated intraocular damage are the prognostic factors for favourable visual outcomes. ${ }^{10} \mathrm{Few}$ reports stated that primary repair followed by pars plana vitrectomy (PPV) and IOL implantation or aphakic correction had good visual outcomes. ${ }^{5,9}$

\section{CONCLUSION}

Pseudophacocele is a rare, serious, and emergency condition following blunt trauma in pseudophakic eyes. Though difficult it is important to manage such cases. Despite proper management, visual outcomes are always compromised.

\section{Conflict of interest: None \\ Source(s) of support: None}




\section{REFERENCES}

1. Thakur S, Ichhpujani P, Kumar S. Pseudophacocele following a bicycle handle injury: A case report. Nepal J Ophthal. 2018 Nov 20;10(1):94-7. [PubMed | Full Text | DOI]

2. Chandravanshi SL, Dwivedi A, Tirkey ER, Choudhary P. Golden half ring sign for identification of pseudophacocele. Indian J Ophthalmol. 2015;63(3):259-61. [PubMed | Full Text | DOI]

3. Assia El, Blotnick CA, Powers TP, Legler UF, Apple DJ. Clinicopathologic study of ocular trauma in eyes with intraocular lenses. Am J Ophthalmol. 1994;117(1):306. [PubMed | Full Text | DOI]

4. Foster JA, Lam S, Joondeph BC, Sugar J. Suprachoroidal dislocation of a posterior chamber intraocular lens. Am J Ophthalmol. 1990;109(6):7312. [PubMed |Full Text |DOI]

5. Kumar A, Nainiwal SK, Dada T, Ray M. Subconjunctival dislocation of an anterior chamber intraocular lens. Ophthalmic Surg Lasers. 2002;33(4):319-20. [PubMed | Full Text | DOI]

6. Kothari M, Asnani P, Kothari K. Anterior dislocation of a sulcus fixated posterior chamber intraocular lens in a high myope. Indian J Ophthalmol. 2008;56(1):7880. [PubMed | Full Text | DOI]

7. Narang $P$, Agarwal A. Clinical outcomes in traumatic pseudo phacocele: A rare clinical entity. Indian J Ophthalmol. 2017;65(12):1465- 9. [PubMed | Full Text | DOI]

8. Biedner B, RothkoffL, Blumenthal M. Subconjunctival dislocation of intraocular lens implant. Am J Ophthalmol. 1977;84(2):265-6. [PubMed | Full Text | DOI]

9. Bandyopadhyay R, Banerjee A, Bhaduri G, Singh M. Traumatic pseudo phacocele. J Indian Med Assoc. 2004;102(12):731. [PubMed | Full Text]

10. Agrawal R, Rao G, Naigaonkar R, Ou X, Desai $S$. Prognostic factors for vision outcome after surgical repair of open globe injuries. Indian J Ophthalmol. 2011;59(6):465-70. [PubMed | Full Text | DOI] 